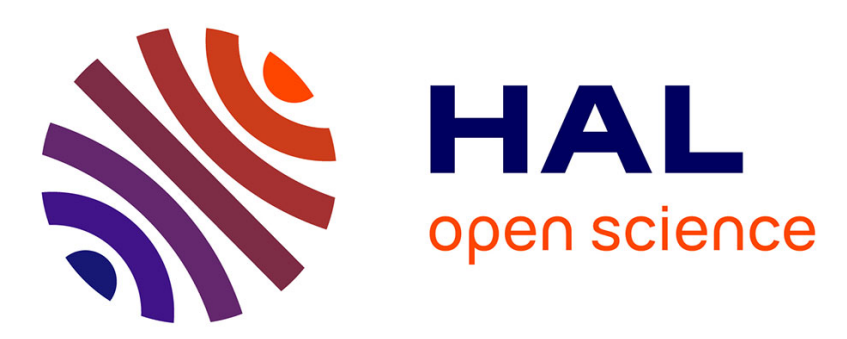

\title{
Object-Oriented Identification of Coherent Structures in Large Eddy Simulations: Importance of Downdrafts in Stratocumulus
}

Florent Brient, Fleur Couvreux, Najda Villefranque, Catherine Rio, Rachel Honnert

\section{To cite this version:}

Florent Brient, Fleur Couvreux, Najda Villefranque, Catherine Rio, Rachel Honnert. Object-Oriented Identification of Coherent Structures in Large Eddy Simulations: Importance of Downdrafts in Stratocumulus. Geophysical Research Letters, 2019, 46 (5), pp.2854-2864. 10.1029/2018GL081499 . hal02414447

\section{HAL Id: hal-02414447 \\ https://hal.science/hal-02414447}

Submitted on 31 Aug 2021

HAL is a multi-disciplinary open access archive for the deposit and dissemination of scientific research documents, whether they are published or not. The documents may come from teaching and research institutions in France or abroad, or from public or private research centers.
L'archive ouverte pluridisciplinaire HAL, est destinée au dépôt et à la diffusion de documents scientifiques de niveau recherche, publiés ou non, émanant des établissements d'enseignement et de recherche français ou étrangers, des laboratoires publics ou privés.

$$
\text { Copyright }
$$




\section{Geophysical Research Letters}

\author{
RESEARCH LETTER \\ 10.1029/2018GL081499 \\ Key Points: \\ - Boundary-layer coherent \\ structures are identified as objects \\ in a stratocumulus large eddy \\ simulation \\ - Both downdrafts and updrafts \\ contribute significantly to heat \\ and moisture transport, although \\ covering only a small fraction of the \\ domain \\ - A mass-flux parameterization \\ is appropriate for representing \\ downward transport within \\ stratocumulus-topped boundary \\ layer in climate models
}

Supporting Information: - Supporting Information S1

Correspondence to:

F. Brient,

florent.brient@gmail.com

Citation:

Brient, F., Couvreux, F., Villefranque, N., Rio, C., \& Honnert, R. (2019). Object-oriented identification of coherent structures in large eddy simulations: Importance of downdrafts in stratocumulus. Geophysical Research Letters, 46, 2854-2864. https://doi.org/10.1029/2018GL081499

Received 29 NOV 2018 Accepted 6 FEB 2019

Accepted article online 11 FEB 2019 Published online 4 MAR 2019

(C)2019. American Geophysical Union. All Rights Reserved.

\section{Object-Oriented Identification of Coherent Structures in Large Eddy Simulations: Importance of Downdrafts in Stratocumulus}

\author{
Florent Brient $^{1}{ }^{(D)}$, Fleur Couvreux ${ }^{1}\left(\mathbb{D}\right.$, Najda Villefranque ${ }^{1,2}$, Catherine Rio $^{1}$, \\ and Rachel Honnert ${ }^{1}$ (D) \\ ${ }^{1}$ CNRM, Université de Toulouse, Météo-France, CNRS, Toulouse, France, ${ }^{2}$ Laboratoire Plasma et Conversion d Energie \\ (LAPLACE), UMR 5213 CNRS, Université Toulouse III, Toulouse, France
}

\begin{abstract}
A novel methodology is proposed to characterize coherent structures in large eddy simulations. Based on two passive tracers emitted respectively at the surface and at cloud top, the object-oriented framework allows individual characterization of coherent tridimensional plumes within the flow. Applying this method in a simulation of the diurnal cycle of a marine stratocumulus-topped boundary layer shows that coherent updraft and downdraft structures contribute to most of the total transport of heat and moisture, although covering a small part of the domain volume. On average, downdrafts contribute equally compared to updrafts for moisture fluxes and more than updrafts for heat fluxes. The relative contribution of updraft and downdraft objects to heat transport exhibits a large diurnal cycle, which suggests cloud-turbulence-radiation interaction. Our results suggest that subgrid downdraft properties within stratocumulus-topped boundary layers should be represented through nonlocal mass-flux parameterization in climate models.
\end{abstract}

Plain Language Summary The representation of marine stratocumulus remains significantly biased in climate models, which lead to important uncertainties in the simulation of the present-day climate and in projections of future climate change. These errors are related to the way boundary-layer clouds are represented through empirically defined parameterizations. To improve cloud representation, we need better understanding of boundary layer processes. Here we use a novel methodology that use passive tracers to define as objects individual coherent structures. One advantage of this framework is that it does not have a priori assumption of flow characteristics for defining them. Although occupying a small part of the volume, those structures carry most of heat and moisture within a diurnal cycle of a stratocumulus-topped boundary layer. We found that downdrafts plumes contribute as much as updrafts to these transports. Contrary to what is used in most of boundary layer parameterizations, the object-oriented analysis suggests that nonlocal mass-flux assumptions are more appropriate for representing downdrafts in climate models.

\section{Introduction}

Marine stratocumulus clouds prevail over the eastern parts of oceans, covering a large area and reflecting a large part of the incoming solar radiation back to space. This makes stratocumulus a major actor in Earth's radiation budget (Hartmann et al., 1992; Chen et al., 2000). Climate models have difficulties in representing these low clouds, mostly because of uncertainties associated with subgrid parameterized processes (Nam et al., 2012; Mechoso et al., 2014; Dal Gesso et al., 2015). Errors in low clouds then drive a part of surface biases (De Szoeke et al., 2012; Hourdin et al., 2015), uncertainties in climate feedbacks (Ceppi et al., 2017) or circulation biases (Adam et al., 2017) in climate models. Improving physical assumptions on cloud representation remains a difficult yet essential challenge for the climate science.

The marine stratocumulus-topped boundary layer consists in a relatively thin cloud deck above a well-mixed layer. The strong and thin inversion layer atop the boundary layer maintains saturation below by avoiding mixing with the warmer and drier free troposphere (Wood, 2012). Convective instability is mostly driven by cloud top radiative cooling that influences downward turbulent motions (Lilly, 1968). Conversely, surface-driven turbulent fluxes mostly influence upward motions (Nicholls, 1984, 1989; Caldwell et al., 2005). The life cycle of clouds is also influenced by small-scale processes such as cloud top entrainment that 
modifies boundary layer buoyancy transport through either mixing, wind shear, or evaporative and radiative cooling (Yamaguchi \& Randall, 2012; Mellado, 2017). The difficulty in representing stratocumulus in climate models is related to the small vertical extent over which these processes occur and to the complexity of the condensation-radiation-turbulence interactions.

Unified approaches have been developed for representing the boundary layer mixing by both turbulent eddies and convective cells and its coupling with cloud and condensation processes (e.g., Hourdin et al., 2002; Siebesma et al., 2007; Rio \& Hourdin, 2008; Neggers et al., 2009; Pergaud et al., 2009; Gentine et al., 2013; Sušelj et al., 2013; Tan et al., 2018). These studies are based on the assumption that convective motions are organized as coherent turbulent structures (e.g., updrafts) that carry most of the heat and moisture within the boundary layer (Nicholls, 1989; Williams \& Hacker, 1992). However, parameterizations rarely represent explicitly the impact of downdrafts on the nonlocal turbulent mixing, and it remains an open question whether local diffusion is accurate enough for representing subgrid downdraft transport.

A preliminary step for investigating this question consists in identifying coherent structures in the boundary layer. Large eddy simulations (LESs) have often been used to provide insight into convective structures and understand the main physical mechanisms involved in them. Coherent structures are usually defined as parts of the flow that have logical interconnections and form a unified whole (Fiedler, 1988). However, identifying these structures is often case specific and based on statistical clustering (Raupach, 1981) related to vertical velocity (e.g., Nicholls, 1989; Schumann \& Moeng, 1991), conservative variables (e.g., Berg \& Stull, 2004), and/or passive tracers (e.g., Couvreux et al., 2010; Park et al., 2016). Recently, some studies analyzed these structures in stratocumulus simulations using various classifications (e.g., Yamaguchi \& Randall, 2012; Chinita et al., 2018). Specifically, the octant classification used in Davini et al. (2017) highlights that updrafts, downdrafts, and cloud top entrainment contribute significantly to the stratocumulus-topped boundary layer turbulent transport of mass, heat, and moisture. Yet those methods present certain limitations: (1) Coherent structures are usually defined from, and thus depend on, flow characteristics such as vertical velocity; (2) the coherence of identified structures is not necessarily established; and (3) some underlying assumptions reduce the efficiency of the identification, for example, removing the incoherent part of the flow or distinguishing downdrafts from entrainment structures.

In this paper, we analyze coherent boundary layer structures using an object-oriented identification applied on a marine stratocumulus LES (section 2). Objects made of contiguous grid cells with positive anomalies of passive tracer concentrations allow the characterization of updraft and downdraft properties and the quantification of their contribution to fluxes (section 3). The potential of this framework for building boundary layer parameterizations is then discussed (section 4) and conclusions are summarized in section 5.

\section{Object-Oriented Coherent Structures}

\subsection{Stratocumulus Simulation}

We use the Meso-NH model version 5.3.1 (Lac et al., 2018) to reproduce the diurnal cycle of marine stratocumulus. Initial conditions and forcing are provided by the First International Satellite Cloud Climatology Project (ISCCP) Regional Experiment (FIRE) model intercomparison study (Duynkerke et al., 2004). The domain size is $25.6 \times 25.6 \times 1.2 \mathrm{~km}^{3}$ with $50-\mathrm{m}$ horizontal resolution and 10-m vertical resolution, large enough for the generation of mesoscale cloud cells (de Roode et al., 2004; Duynkerke et al., 2004). The simulation is run for $24 \mathrm{hr}$, and outputs are saved every $3 \mathrm{hr}$. Two passive tracers emitted respectively at the surface $\left(s_{1}\right)$ and at one grid layer above the domain-averaged cloud top height $\left(s_{2}\right)$ have been added to the simulation, in which the latter aims to follow air parcels that were entrained from the free troposphere. Both tracers decay with a time scale of $30 \mathrm{~min}$ as in Couvreux et al. (2010). Model description, simulation setup and details on tracer emission are described in the supporting information.

The cloud pattern shows evolving mesoscale organization with time (Figures 1a and 1b): from circular clouds at noon to large elongated cloud bands at midnight. Overall, these cloud patterns are very similar to observed closed cell organization (e.g., Wood \& Hartmann, 2006). Despite areas of weaker-than-average cloud liquid water content, the simulation remains overcast in time (i.e., no cloud holes are present in this simulation).

The daytime cloud thickness along a vertical cross section ranges from 100 to $300 \mathrm{~m}$, while the nighttime cloud thickness is almost uniformly $300 \mathrm{~m}$ (Figures 1c and 1d). Positive anomalies of surface-emitted tracer $s_{1}$ concentrations (relative to the domain average at each level) are organized into plumes with upward 

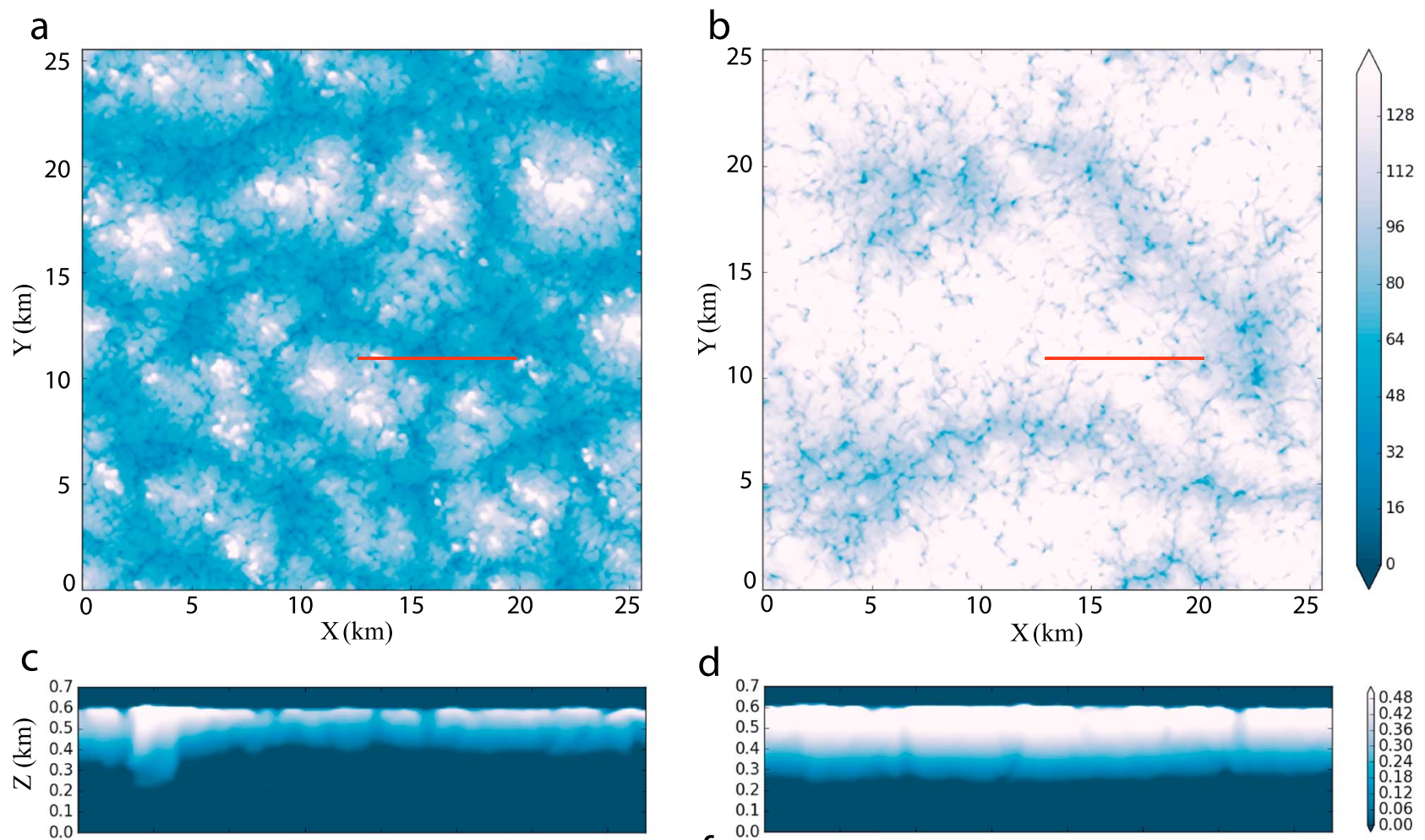

d
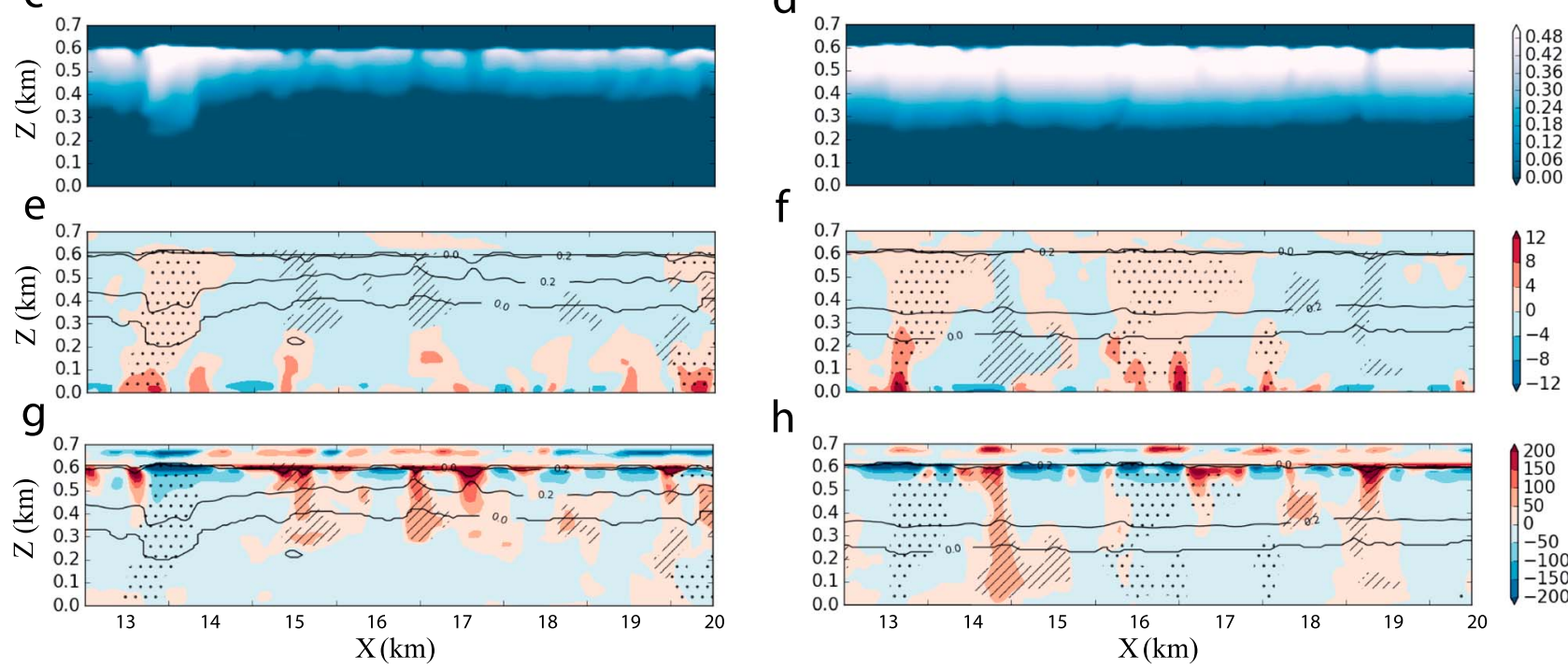

h

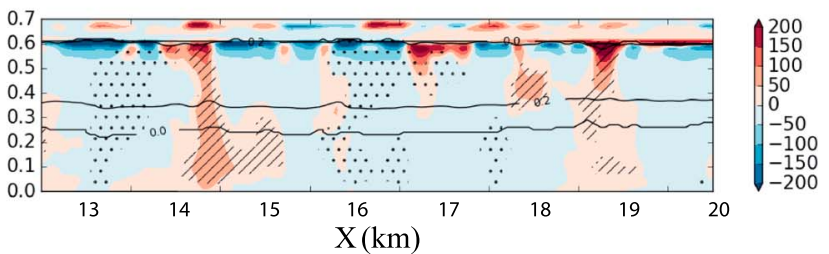

Figure 1. Snapshots of $(\mathrm{a}, \mathrm{b})$ liquid water path $\left(\mathrm{g} / \mathrm{m}^{2}\right)$ and vertical cross sections along the horizontal red line $(x=12.5-20 \mathrm{~km}, y=11 \mathrm{~km})$ for $(\mathrm{c}$, d) liquid water mixing ratio $(\mathrm{g} / \mathrm{kg})$ and for anomalies of $(\mathrm{e}, \mathrm{f})$ surface-emitted tracers and of $(\mathrm{g}, \mathrm{h})$ cloud top emitted tracers relatively to horizontal average. Objects representing updrafts and downdrafts are shown as dotted and hatched patterns, respectively. Contours representing liquid water contents of 0.0 and $0.2 \mathrm{~g} / \mathrm{kg}$ are overlaid on $\mathrm{e}-\mathrm{h}$. Left and right columns are snapshots at $t=12 \mathrm{hr}$ and $t=24 \mathrm{hr}$ respectively.

vertical velocity that sometimes penetrate the cloud layer and reach the cloud top (Figures 1e and 1f). These updrafts are associated with thicker cloud layers. Free-troposphere tracers penetrate the cloud layer along downward plumes, which end at the cloud base at noon but reach the surface at nighttime (Figure $1 \mathrm{~g}$ and 1h). These air intrusions are associated with weaker-than-average liquid water content.

\subsection{Object Identification}

In order to identify coherent structures, we construct objects from anomalies of passive tracer $s_{1}$ and $s_{2}$ concentrations. First, the "conditional sampling" (CS) selects grid boxes that contain sufficiently large anomalies of tracer concentrations (see below). Second, objects are defined as ensembles of contiguous selected grid boxes built in a three-dimensional space. Here "contiguous" means sharing either a face, an edge, or a corner. Third, identified objects with a smaller volume than $V_{\min }$ are filtered out.

The selection of grid cells $(x, y, z)$ included in the CS is based on Couvreux et al. (2010):

$$
\left\{(x, y, z) \in C S \quad \mid \quad s^{\prime}(x, y, z)>\sigma(z)\right\}
$$



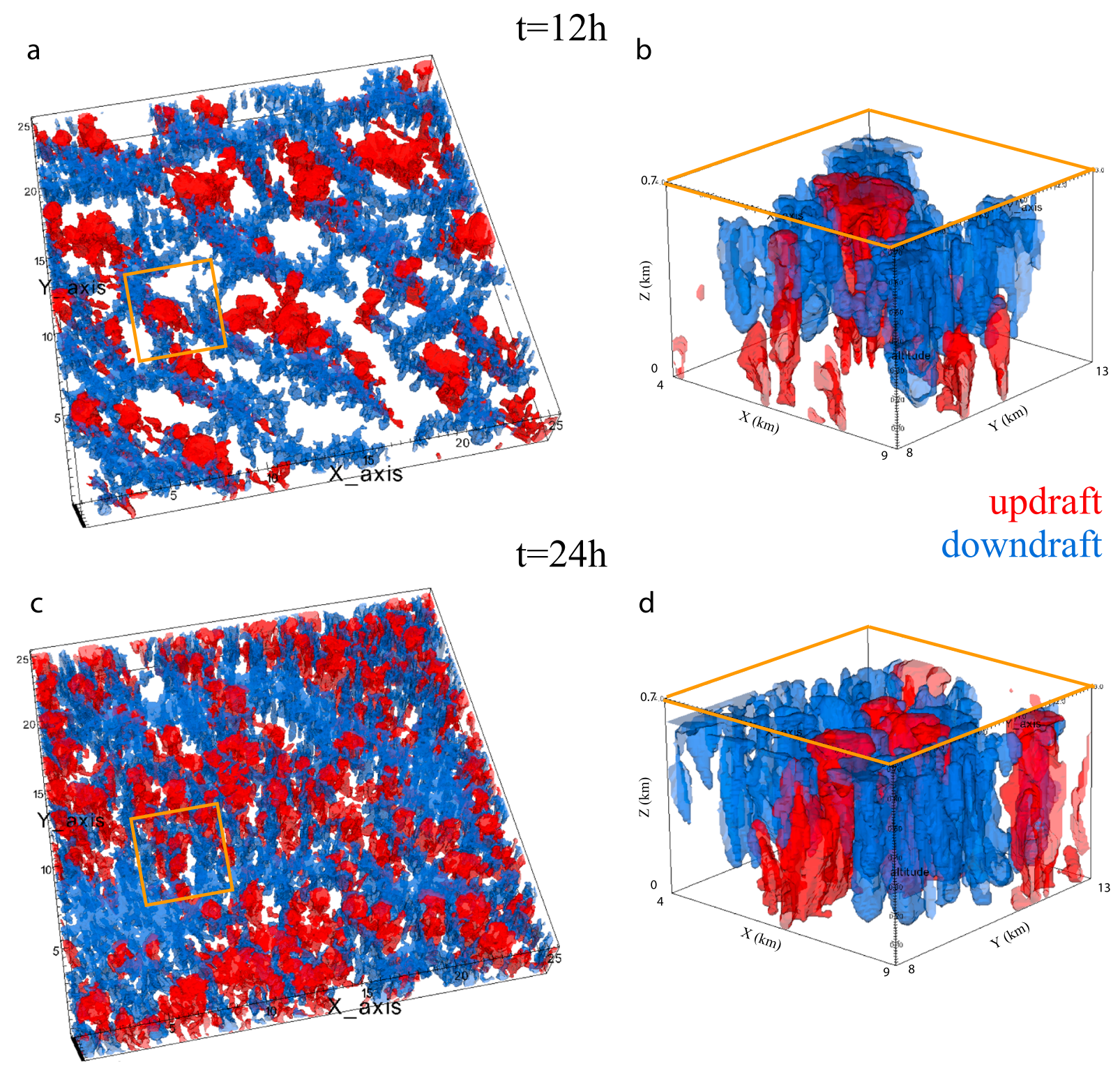

Figure 2. Visualization of updraft and downdraft objects at $t=12 \mathrm{hr}$ and $t=24 \mathrm{hr}$ for (a, c) the entire domain and (b, d) a focus on a small subdomain (orange square, $x=4-9 \mathrm{~km} ; y=8-13 \mathrm{~km}$ ). Objects are sampled using $m=1$ and $V_{\min }=0.25 \mathrm{~km}^{3}$.

with $s^{\prime}$ the tracer anomaly concentration relative to the horizontal mean $(\bar{s})$ and $\sigma(z)$ the horizontal mean threshold at altitude $z$, defined as

$$
\begin{gathered}
\sigma(z)=m \times \max \left(\sigma_{s}(z), \sigma_{\min }(z)\right) \\
\text { with } \sigma_{\min }(z)=L \cdot \frac{0.05}{z-z_{1}} \int_{z_{1}}^{z} \sigma_{s}(z) \mathrm{d} z
\end{gathered}
$$

and $\sigma_{s}(z)$ being the standard deviation of the tracer concentration $s$ at altitude $z$ and with $L=1$ for $s_{1}$ and $L=-1$ for $s_{2}$. The minimal threshold $\sigma_{\min }$ is used to underrepresent layers with low tracer concentrations and thus weak standard deviation (i.e., filtering out the nonturbulent free troposphere for $s_{1}$ and the lowest layers for $s_{2}$ ). For $s_{1}$, we choose $z_{1}$ the surface for the bottom-up integration to the domain top. For $s_{2}, z_{1}$ is the altitude of tracer emission (plus half a layer) for the top-down integration to the surface. Unlike a majority of CSs (e.g., Siebesma \& Cuijpers, 1995; Couvreux et al., 2010; Park et al., 2016; Davini et al., 2017), the identification of coherent structures is not related to any flow characteristic (e.g., vertical velocity 

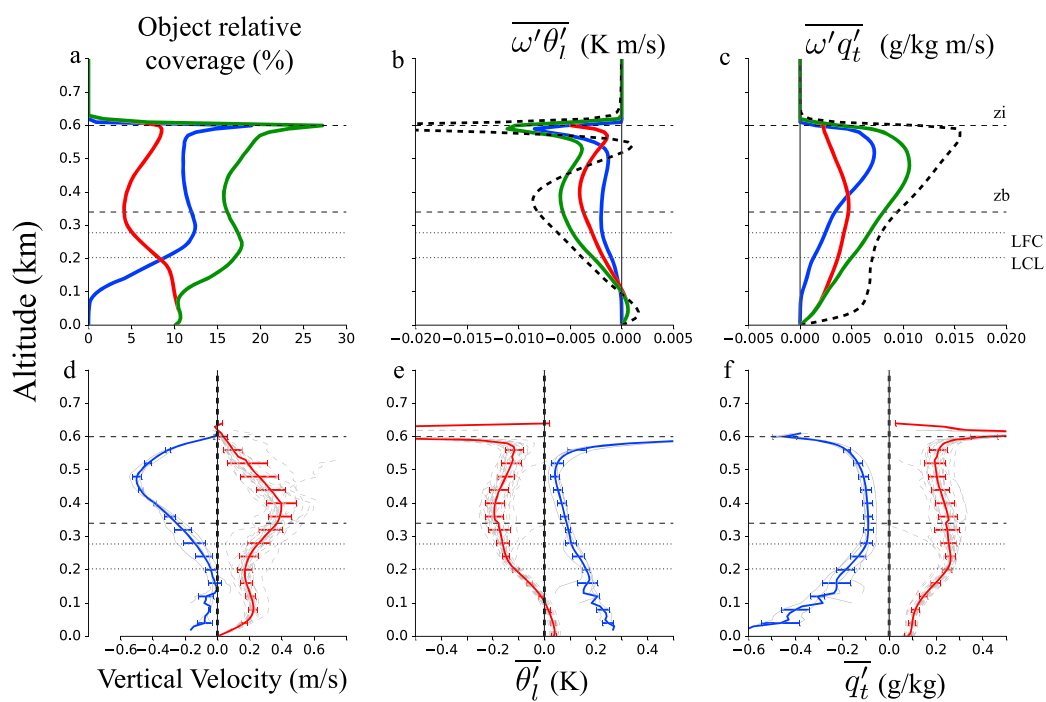

Updraft or Downdraft

Updraft

Downdraft
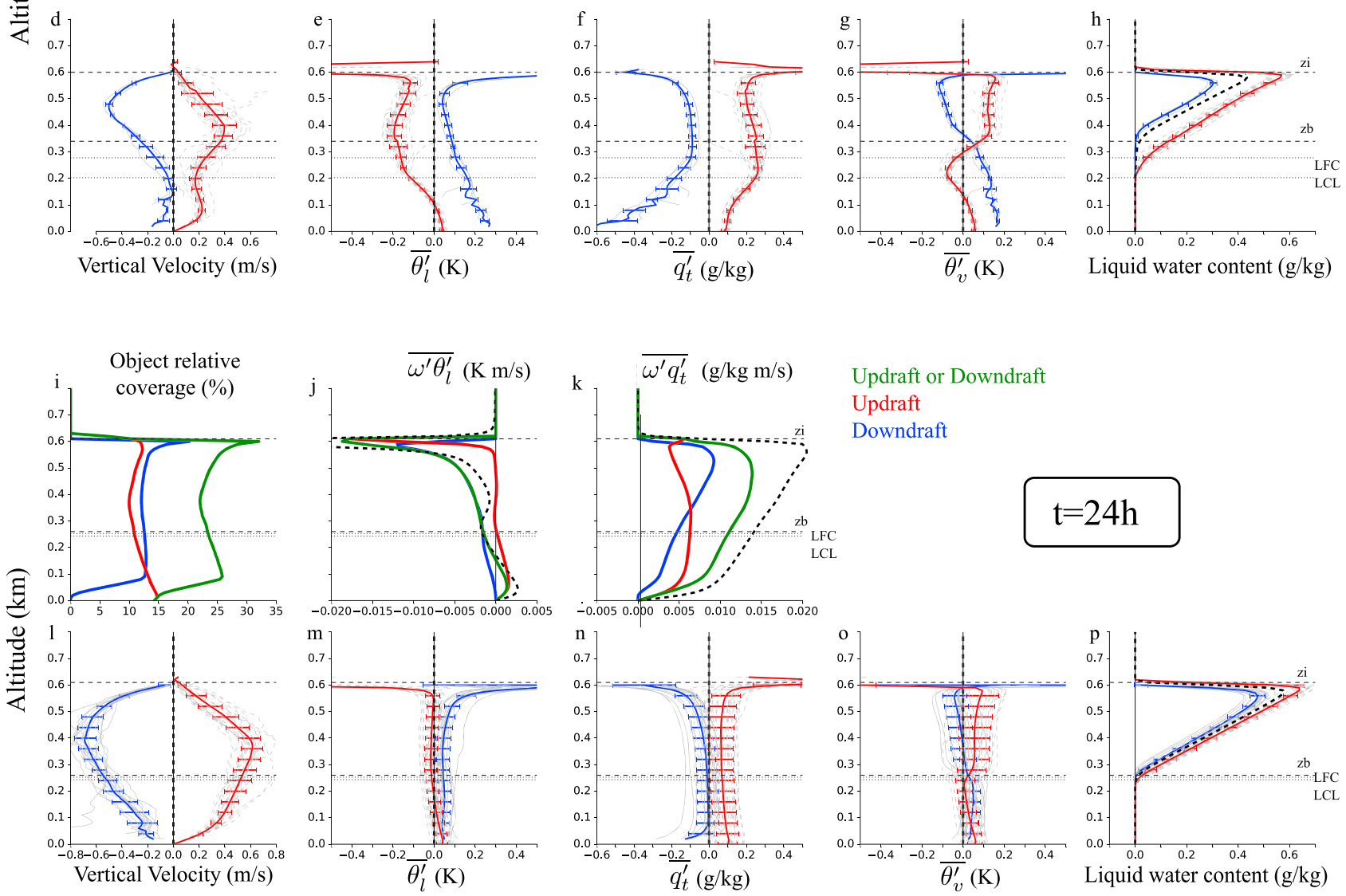
Updraft or Downdraft
Updraft
Downdraft

\section{$\mathrm{t}=12 \mathrm{~h}$}

\section{$\mathrm{t}=24 \mathrm{~h}$}
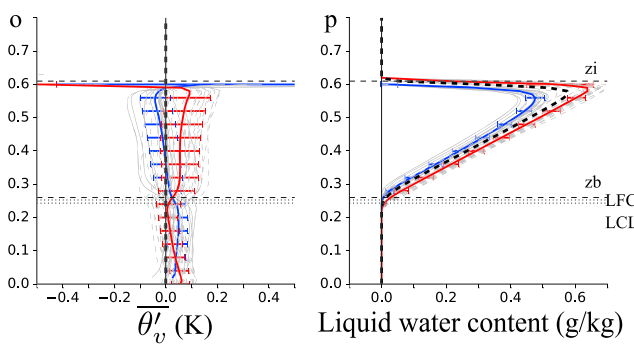

Figure 3. Domain-averaged vertical profiles of (a-i) object relative coverage, (b-j) liquid water potential temperature resolved fluxes and (c-k) total humidity resolved fluxes, (d-1) vertical velocities, anomalies of (e-m) liquid water potential temperature, ( $\mathrm{f}-\mathrm{n})$ total humidity and (g-o) virtual potential temperature, and average liquid water content at (top) $t=12 \mathrm{hr}$ and (bottom) $t=24 \mathrm{hr}$. Red and blue profiles correspond to average characteristics of the updraft and downdraft objects, respectively. Object contributions to fluxes are weighted by their relative coverage. Average profiles (green) correspond to grid boxes satisfying either the downdraft or the updraft conditional sampling. Domain-mean resolved fluxes and liquid water contents are shown as dashed black lines. Individual object characteristics are represented as gray lines and horizontal color lines are the interobject standard deviation. Domain-mean lifting condensation level (LCL), level of free convection (LFC), cloud base (zb), and cloud height (zi) are also shown. Objects are sampled using $m=1$ and $V_{\min }=0.25 \mathrm{~km}{ }^{3}$.

and liquid water). Even though the sign of vertical velocity is not imposed, we call updraft objects (downdraft objects) coherent structures defined through surface-emitted tracers $\left(s_{1}^{\prime}\right)$ (cloud top-emitted tracers, $s_{2}^{\prime}$ ) as they consist of upward (downward) flow as shown later. Applying criteria on vertical velocity does not significantly influence our results (supporting information). The "total object" grid boxes belong either to updraft or downdraft objects. Finally, the scaling factor $m$ (equation (2)) is a tunable parameter that quantifies the strength of the CS. In the following, we show results using $m=1$ and $V_{\min }=0.25 \mathrm{~km}^{3}$ (i.e., $10^{4}$ cells), values that maximize the object contribution to the boundary layer transport with minimum volume. We discuss the sensitivity of our results to these values in the supporting information.

The cross sections seen in Figures 1e-1h show that the majority of objects are spread out between the surface and cloud top. However, some of them end at the cloud base especially during daytime. Overall, objects rarely overlap each other. Figure 2 better highlights the mesoscale organization of objects. Areas associated 
with thicker/thinner cloud areas are associated with a denser concentration of updraft/downdraft objects (see Figures 1a and 1b for liquid water path). Mesoscale organization of downdrafts mostly forms a network during daytime whereas updrafts are more gathered together. Nighttime organization is more random. Individually, updrafts and downdrafts consist in vertically developed narrow plumes, with larger sizes at nighttime. This confirms that the object-oriented framework well identifies coherent structures within the mesoscale organization.

\section{Object Characteristics and Contribution to Boundary Layer Fluxes}

\subsection{Updraft and Downdraft Properties}

Domain-averaged object characteristics are shown in Figure 3. Daytime and nighttime objects cover around $18 \%$ and $23 \%$ of the boundary layer volume respectively. Updrafts cover around $7 \%$ of the domain volume at $t=12 \mathrm{hr}$ with local minimum coverage at the cloud base, which suggests that only some updrafts penetrate the cloud layer (Figure 3a). Downdrafts cover around $9 \%$ of the domain volume at $t=12 \mathrm{hr}$ with maximum coverage at cloud top (17\%), a more or less constant fraction further in the cloud layer (12\%) and a minimum coverage below the level of free convection. This suggests that penetrative free tropospheric air parcels mix within the cloud layer then dissipate below cloud base. The vertical profiles of object relative coverage highlight boundary layer decoupling at noon, consistent with the different altitudes of the domain-averaged cloud base and the lifting condensation level (LCL; Jones et al., 2011). At $t=24 \mathrm{hr}$, decoupling vanishes and both updraft and downdraft objects cover a larger part of the domain almost uniformly with height (around $12 \%$ and $13 \%$ coverage, respectively, Figure $3 i$ ).

Despite the fact that sampled parcels are not constrained by the sign of vertical velocity, updraft and downdraft objects have positive and negative velocities, respectively (Figures $3 \mathrm{~d}$ and $3 \mathrm{l}$ ). At $t=12 \mathrm{hr}$, unsaturated parcels are entrained, become saturated, and undergo downward acceleration within $100 \mathrm{~m}$ below the cloud top with maximum speed of $-0.5 \mathrm{~m} / \mathrm{s}$ then decelerate slowly until reaching the cloud base. Each downdraft object is positively buoyant at the cloud top and negatively buoyant within the first $20 \mathrm{~m}$ below (Figures $3 \mathrm{~g}$ and 3o). This sharp transition likely triggers downward motion. Buoyancy remains negative until about $20 \mathrm{~m}$ above cloud base and stays positive below. Downdrafts are also associated with negative anomalies of total water mixing ratio and positive anomalies of liquid potential temperature, tracing back their origins from the free troposphere (Figures $3 \mathrm{e}-3 \mathrm{f}$ and $3 \mathrm{~m}-3 \mathrm{n}$ ). While daytime downdrafts are mostly constrained within the cloud layer, nighttime entrained parcels sink deeper and accelerate more strongly (around $-0.7 \mathrm{~m} / \mathrm{s}$ ), which allows a majority of them to reach the surface. This is related to a coupled boundary layer at nighttime. Nighttime downdrafts share similar features than daytime downdrafts (e.g., cloud top buoyancy reversal and wet and warm anomalies) but with weaker intensities.

Daytime updraft objects display two vertical velocity maxima, one in the middle of the subcloud layer and one around the domain-averaged cloud base (Figure 3d). Penetrative updrafts thus undergo two accelerations: the first, induced by surface fluxes and the second, related to latent heat release by condensation. Buoyancy is generally positive yet with a negative anomaly around the LCL, which is a signature of a cumulus-coupled boundary layer (Bretherton, 1997; Wood, 2012). Finally, the buoyancy anomaly becomes negative around cloud top probably in relation to warm parcels overshooting in colder layers. At $t=24 \mathrm{hr}$, updrafts only show a unique vertical velocity maximum in the middle of the cloud layer (Figure 31). As for downdrafts, nighttime updraft characteristics are consistent with daytime updrafts yet with weaker anomalies. Finally, daytime individual object properties are very consistent with one another. This is slightly less true at nighttime.

\subsection{Contribution to Turbulent Fluxes}

The relative contributions of updrafts and downdrafts to the vertical turbulent transport of heat $\left(\overline{\omega^{\prime} \theta_{l}^{\prime}}\right)$ and moisture $\left(\overline{\omega^{\prime} q_{t}^{\prime}}\right)$ are now investigated, focusing only on the resolved fluxes. At altitude $z$, the vertical transport can be decomposed into a sum of different object contributions $F_{i}$ such as

$$
\begin{gathered}
\overline{\omega^{\prime} \phi^{\prime}}(z)=\sum_{i \in\{u, d, e\}} F_{i}(\phi, z) \\
\text { with } F_{i}(\phi, z)=\frac{1}{N} \sum_{(x, y) \in i}(\omega(x, y, z)-\bar{\omega}(z)) \cdot(\phi(x, y, z)-\bar{\phi}(z)) ;
\end{gathered}
$$


$\times$ Updraft

- Downdraft

O Updraft \& Downdraft

- Updraft or Downdraft

a

\section{Object volume ratio (\%)}
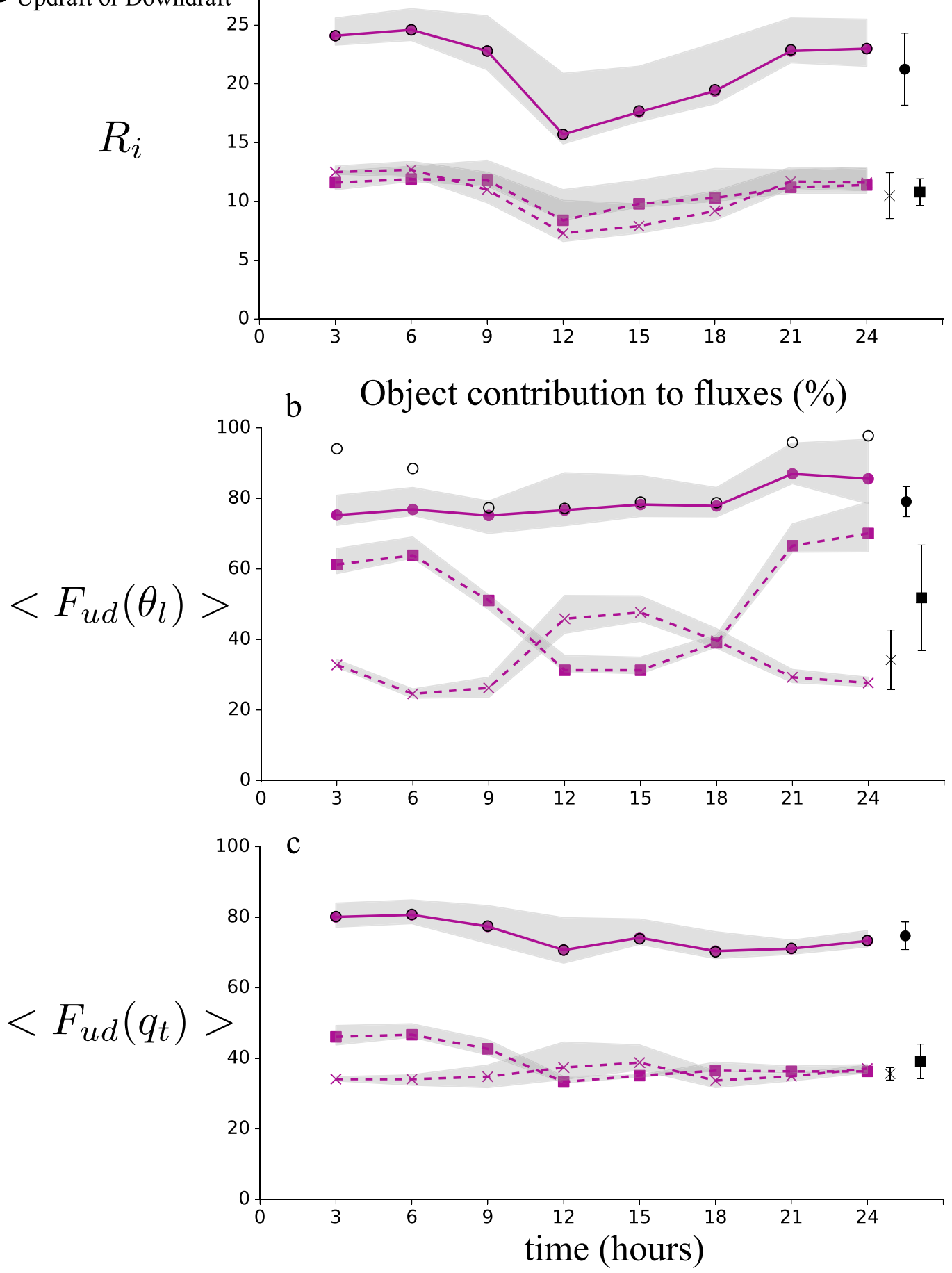

Figure 4. Diurnal cycle of (a) the object volume ratio $R_{i}(\%)$ and of the vertically averaged object contribution to the domain-mean resolved flux (\%) of (b) heat $\left\langle F_{\mathrm{ud}}\left(\theta_{l}\right)\right\rangle$ and (c) moisture $\left\langle F_{\mathrm{ud}}\left(q_{t}\right)>\right.$. Signs represent computations using $m=1$ and $V_{\min }=0.25 \mathrm{~km}^{3}$. Black signs on the right are time-averaged values with standard deviations. Updrafts and downdrafts are represented as cross and square signs, respectively. Full circles refer to objects satisfying either updraft or downdraft conditional sampling, while empty circles represent the sum of updrafts and downdrafts. Gray shades represent uncertainties related to $V_{\min }$. 
$\phi$ is a conservative variable $\left(\theta_{l}\right.$ or $\left.q_{t}\right) ; N$ is the number of horizontal cells; bars and primes represent the horizontal mean and anomalies relative to this average. $F_{i}$, which quantifies the relative contribution of each component to the boundary layer turbulent transport, is the sum of the top-hat contribution to fluxes and the covariance within structures (Siebesma \& Cuijpers, 1995; Wang \& Stevens, 2000; Chinita et al., 2018). Figure 3 shows the updraft $\left(F_{\mathrm{u}}\right)$, downdraft $\left(F_{\mathrm{d}}\right)$, and total $\left(F_{\mathrm{ud}}\right)$ object contributions to domain-mean heat $(b, j)$ and moisture (c, k) fluxes. Despite covering a relative small fraction of the full domain ( $\approx 20 \%)$, objects contribute to most of the vertical transport of heat and moisture. The remaining contribution is probably related to local transport by small-scale eddies. The negative cloud top heat flux is slightly underestimated by objects both at daytime and nighttime. Objects also do not represent the weak positive daytime heat flux just below the cloud top and underestimate the subcloud heat transport, which is partly carried by small-scale objects (filtered out by our choice in $V_{\min }$ ). Nighttime object heat fluxes better reproduce the total flux, mostly through the downdraft contribution. The object contribution to domain-averaged moisture vertical fluxes is important at both daytime and nighttime, and the relative updraft/downdraft contributions are maximum below/above $350 \mathrm{~m}$, respectively. Nighttime vertical relative coverage of coherent structures and its flux partitioning between updraft and downdraft are in agreement with Chinita et al. (2018).

\subsection{The Diurnal Cycle of Object Characteristics}

The variability of object characteristics is now analyzed throughout an entire diurnal cycle. First, the ratio $R_{i}$ of the volume filled by objects to the domain volume below $620 \mathrm{~m}$ (i.e., just above the cloud top) is defined as

$$
R_{i}=\frac{\int_{z} \alpha_{i}(z) \cdot S \cdot \mathrm{d} z}{\int_{z} S \cdot \mathrm{d} z}
$$

with $S$ the surface of the domain $\left(S=25.6 \times 25.6 \mathrm{~km}^{2}\right), \mathrm{d} z$ the vertical resolution $(\mathrm{d} z=10 \mathrm{~m}) ; \alpha_{i}$ is the fractional coverage of either updraft (u) or downdraft (d) objects, as seen in Figures $3 \mathrm{a}$ and $3 \mathrm{i}$, or the remaining area being called the environment (e) with

$$
\alpha_{\mathrm{u}}(z)+\alpha_{\mathrm{d}}(z)+\alpha_{\mathrm{e}}(z)=1
$$

Using aforementioned thresholds for object detection, the volume ratio $R_{i}$ has a significant diurnal cycle with minimum amplitude at noon (15\%) and maximum during nighttime (around 23\%), with updraft objects contributing slightly more than downdrafts to the diurnal variability (Figure 4a). On average, objects cover $21 \pm 3 \%$ of the domain volume with updraft and downdraft objects contributing almost equally to this ratio $(10 \pm 2 \%$ and $11 \pm 1 \%$, respectively).

We then quantify the vertically averaged object contribution to domain-averaged resolved fluxes $<F_{i}(\phi)>$ defined as

$$
<F_{i}(\phi)>=\frac{\int_{z}\left|F_{i}(\phi, z)\right|}{\int_{z}\left|\overline{\omega^{\prime} \phi^{\prime}}(z)\right|}
$$

with $F_{i}(\phi, z)$ defined in equation (5). Figure 4 shows the diurnal evolution of heat and moisture fluxes. Objects carry out most of the heat inside the boundary layer $(79 \pm 4 \%)$, with no significant diurnal variability. However, contributions of either updrafts or downdrafts do have large diurnal cycles, with updrafts carrying most of the heat at daytime $(\approx 45 \%)$ and downdrafts at nighttime $(\approx 65 \%)$. This difference is related to daytime heating, which reduces cloud top cooling and favors upward motions (Figures $3 \mathrm{~b}$ and $3 \mathrm{j}$ ). On average, downdrafts carry more heat than updrafts (52 $\pm 15 \%$ and $34 \pm 8 \%$, respectively). Figure $4 \mathrm{c}$ shows that selected objects are also responsible for most of the moisture transport in the boundary layer $(74 \pm 4 \%)$, with no significant diurnal cycles. Both downdrafts and updrafts contribute equally to the total flux contribution ( $39 \pm 5 \%$ and $36 \pm 2 \%$, respectively). Finally, Figures $4 \mathrm{~b}$ and $4 \mathrm{c}$ show that the total object contribution is equal to the sum of updraft and downdraft contributions taken independently, except at nighttime where difference between them can reach 10-20\% (Figure 4b). This suggests that updraft and downdraft heat flux contributions are slightly overestimated at nighttime due to overlapping effects. Uncertainties related to the choice $V_{\min }$ do not significantly influence these results (Figure 4). 


\section{Implication for Parameterization Development}

Our results suggest that downdrafts significantly contribute to the transport of heat and moisture within a stratocumulus-topped boundary layer. Downward motions are usually represented through local eddy diffusion (that can be related to the radiative cooling, e.g., Lock et al., 2000) or compensating subsidence in climate models. It is not clear, however, to what extent these assumptions remain trustworthy. Our analysis of coherent structures suggests several implications for boundary layer parameterizations aiming to represent marine stratocumulus:

1. Given their importance in transporting heat and moisture, both updrafts and downdrafts should be represented in climate models. Downward structures expand vertically in the entire cloud layer and may reach the surface, which suggests that they are associated with nonlocal transport. This supports the need for a mass-flux parameterization dedicated to the representation of downdrafts.

2. The properties of downdrafts do not vary much from one object to the other. The object-oriented framework provides individual statistics of each plume (size, shape, buoyancy, energy, etc.) that can be useful to validate a multiplume parameterization (e.g., Neggers et al., 2009; Sušelj et al., 2013) or justify the use of a bulk parameterization.

3. The use of passive tracers above the cloud top helps tracking the onset of downdraft coherent structures by informing about processes of buoyancy reversal instability. Several mechanisms have been highlighted to explain this triggering such as radiative cooling (Lilly, 1968), evaporative cooling (Kuo \& Schubert, 1988), wind shear (Mellado, 2017) or turbulent mixing (Yamaguchi \& Randall, 2012). Statistics of downdrafts provided by this framework could be used to infer a parameterization of downdraft initiation.

4. The diurnal cycle of updraft and downdraft contributions to boundary layer fluxes suggests that future parameterization development needs to include source and sinks of heat linked to cloud-radiation interactions.

\section{Conclusions}

In the present work, we analyze updraft and downdraft properties using a methodology identifying coherent structures in LESs based on two passive tracers emitted respectively at the surface and just above cloud top. Based on Couvreux et al. (2010) CS, this framework goes a step further by identifying objects as ensembles of contiguous grid boxes rich in concentration of such tracers that correspond to updraft and downdraft structures. Contrary to previous methodologies, our sampling framework does not have a priori assumptions, neither on vertical velocity nor on thermodynamical variables (e.g., potential temperature and liquid water), making that the identified objects only depend on spatial heterogeneity led by coherent internal motions but not on any flow characteristics.

This study focuses on the diurnal cycle of marine stratocumulus using the FIRE framework (Duynkerke et al., 2004) in an LES run by the Meso-NH model. At nighttime, we confirm the importance of downdrafts in carrying heat and moisture within the boundary layer (Davini et al., 2017; Chinita et al., 2018). At daytime, solar heating and boundary layer decoupling strengthen updraft transport and weaken cloud top entrainment. The object-oriented identification highlights the main thermodynamical and dynamical features of updrafts and downdrafts:

- Updrafts are characterized by relatively weak upward vertical velocity, moist, warm, and positively buoyant air. At nighttime, updrafts undergo acceleration from the surface to the middle of the cloudy boundary layer (around $400 \mathrm{~m}$ ). Daytime decoupling weakens vertical velocity around the LCL, which is associated with a reduced number of parcels penetrating the cloud layer. This decoupling strengthens vertical gradients of moisture and temperature, leading to an increase of updraft heat transport at daytime. On average, updraft objects contribute to $34 \pm 8 \%$ and $36 \pm 2 \%$ of the boundary layer transport of heat and moisture, respectively, while covering only $10 \pm 2 \%$ of the domain.

- Downdrafts are characterized by a downward vertical velocity, dry, cool, and negatively buoyant air. However, downdraft tops are positively buoyant, which suggest buoyancy reversal whose instability likely triggers downward plumes. Downdrafts undergo acceleration from the cloud top to around $450 \mathrm{~m}$ and decelerate to the cloud base at noon and until the surface at nighttime. Downdrafts maximize transport of heat and moisture atop the boundary layer and largely contribute to the total transport (52 $\pm 15 \%$ and $39 \pm 5 \%$ ) while occupying only $11 \pm 1 \%$ of the domain volume. Downdrafts carry more heat than updrafts especially at night in this stratocumulus simulation. 
Acknowledgments

This work received funding from grant HIGH-TUNE ANR-16-CE01-0010. It was supported by the DEPHY2 project, funded by the French national program LEFE/INSU. We thank two anonymous reviewers for their insightful comments on the manuscript. We also thank Fabio d'Andrea, Paolo Davini, and Pierre Gentine for interesting discussions on the stratocumulus dynamics, Ross Dixon for proofreading the manuscript, and Stefan De Roode for providing data from the FIRE intercomparison. The model is available on the Meso-NH website (http://mesonh.aero.obs-mip.fr/). Routines for the object identification are available on the Github website (https://gitlab.com/tropics/objects/).
- Overall, structurally coherent objects carry $79 \pm 4 \%$ and $75 \pm 4 \%$ of the transport of heat and moisture, respectively, in the boundary layer while occupying $21 \pm 3 \%$ of the domain volume. The remaining part of the domain $(79 \%)$ only slightly contributes to the boundary layer transport $(\approx 25 \%)$. This partitioning is slightly sensitive to the minimum volume threshold $(\approx 5-10 \%)$.

Further investigation is needed to quantify the relative role of the downdraft structures in different boundary layer situations such as clear-sky conditions (Ayotte et al., 1996; Couvreux et al., 2005), marine cumulus clouds (Brown et al., 2002; Siebesma et al., 2003), and St-to-Cu transition (De Roode et al., 2016). Given that Couvreux et al. (2007) highlighted the existence of downdrafts in clear sky conditions, confirming the existence of such coherent structures in both clear-sky and cloudy conditions would emphasize the need for a parameterization representing the nonlocal downward transport. Furthermore, investigating how clouds change from closed-cell stratocumulus to organized cumulus would likely give insight into the evolving partitioning of flux contribution from updrafts and downdrafts. Finally, the parameterization of cloud top triggering for downdrafts will need further work that could be addressed through the object-oriented framework.

\section{References}

Adam, O., Schneider, T., \& Brient, F. (2017). Regional and seasonal variations of the double-ITCZ bias in CMIP5 models. Climate Dynamics, 51, 101-117.

Ayotte, K. W., Sullivan, P. P., Andren, A., Doney, S. C., Holtslag, A. A., Large, W. G., et al. (1996). An evaluation of neutral and convective planetary boundary-layer parameterizations relative to large eddy simulations. Boundary-Layer Meteorology, 79(1-2), 131-175.

Berg, L. K., \& Stull, R. B. (2004). Parameterization of joint frequency distributions of potential temperature and water vapor mixing ratio in the daytime convective boundary layer. Journal of the Atmospheric Sciences, 61(7), 813-828.

Bretherton, C. (1997). Convection in stratocumulus-topped atmospheric boundary layers. In The physics and parameterization of moist atmospheric convection (pp. 127-142). Dordrecht: Springer.

Brown, A., Cederwall, R., Chlond, A., Duynkerke, P., Golaz, J. C., Khairoutdinov, M., et al. (2002). Large-eddy simulation of the diurnal cycle of shallow cumulus convection over land. Quarterly Journal of the Royal Meteorological Society, 128(582), $1075-1093$.

Caldwell, P., Bretherton, C. S., \& Wood, R. (2005). Mixed-layer budget analysis of the diurnal cycle of entrainment in southeast pacific stratocumulus. Journal of the Atmospheric Sciences, 62(10), 3775-3791.

Ceppi, P., Brient, F., Zelinka, M. D., \& Hartmann, D. L. (2017). Cloud feedback mechanisms and their representation in global climate models. WIREs, 8(4), e465

Chen, T., Rossow, W. B., \& Zhang, Y. (2000). Radiative effects of cloud-type variations. Journal of Climate, 13(1), $264-286$.

Chinita, M. J., Matheou, G., \& Teixeira, J. (2018). A joint probability density-based decomposition of turbulence in the atmospheric boundary layer. Monthly Weather Review, 146(2), 503-523.

Couvreux, F., Guichard, F., Masson, V., \& Redelsperger, J.-L. (2007). Negative water vapour skewness and dry tongues in the convective boundary layer: Observations and large-eddy simulation budget analysis. Boundary-Layer Meteorology, 123(2), $269-294$.

Couvreux, F., Guichard, F., Redelsperger, J.-L., Kiemle, C., Masson, V., Lafore, J.-P., \& Flamant, C. (2005). Water-vapour variability within a convective boundary-layer assessed by large-eddy simulations and ihop_2002 observations. Quarterly Journal of the Royal Meteorological Society, 131(611), 2665-2693.

Couvreux, F., Hourdin, F., \& Rio, C. (2010). Resolved versus parametrized boundary-layer plumes. Part I: A parametrization-oriented conditional sampling in large-eddy simulations. Boundary-Layer Meteorology, 134(3), 441-458.

Dal Gesso, S., Van der Dussen, J., Siebesma, A., De Roode, S., Boutle, I., Kamae, Y., et al. (2015). A single-column model intercomparison on the stratocumulus representation in present-day and future climate. Journal of Advances in Modeling Earth Systems, 7, 617-647. https://doi.org/10.1002/2014MS000377

Davini, P., D'Andrea, F., Park, S.-B., \& Gentine, P. (2017). Coherent structures in large-eddy simulations of a nonprecipitating stratocumulus-topped boundary layer. Journal of the Atmospheric Sciences, 74(12), 4117-4137.

de Roode, S. R., Duynkerke, P. G., \& Jonker, H. J. (2004). Large-eddy simulation: How large is large enough? Journal of the Atmospheric Sciences, 61(4), 403-421.

De Roode, S. R., Sandu, I., Van Der Dussen, J. J., Ackerman, A. S., Blossey, P., Jarecka, D., et al. (2016). Large-eddy simulations of EUCLIPSE-GASS Lagrangian stratocumulus-to-cumulus transitions: Mean state, turbulence, and decoupling. Journal of the Atmospheric Sciences, 73(6), 2485-2508.

De Szoeke, S. P., Yuter, S., Mechem, D., Fairall, C. W., Burleyson, C. D., \& Zuidema, P. (2012). Observations of stratocumulus clouds and their effect on the eastern Pacific surface heat budget along 20 S. Journal of Climate, 25(24), 8542-8567.

Duynkerke, P. G., de Roode, S. R., van Zanten, M. C., Calvo, J., Cuxart, J., Cheinet, S., et al. (2004). Observations and numerical simulations of the diurnal cycle of the EUROCS stratocumulus case. Quarterly Journal of the Royal Meteorological Society, 130(604), 3269-3296.

Fiedler, H. (1988). Coherent structures in turbulent flows. Progress in Aerospace Sciences, 25(3), 231-269.

Gentine, P., Betts, A. K., Lintner, B. R., Findell, K. L., van Heerwaarden, C. C., Tzella, A., \& D'Andrea, F. (2013). A probabilistic bulk model of coupled mixed layer and convection. Part I: Clear-sky case. Journal of the Atmospheric Sciences, 70(6), 1543-1556.

Hartmann, D. L., Ockert-Bell, M. E., \& Michelsen, M. L. (1992). The effect of cloud type on Earth's energy balance: Global analysis. Journal of Climate, 5, 1281-1304.

Hourdin, F., Couvreux, F., \& Menut, L. (2002). Parameterization of the dry convective boundary layer based on a mass flux representation of thermals. Journal of the Atmospheric Sciences, 59(6), 1105-1123.

Hourdin, F., Găinuşă-Bogdan, A., Braconnot, P., Dufresne, J.-L., Traore, A.-K., \& Rio, C. (2015). Air moisture control on ocean surface tem perature, hidden key to the warm bias enigma. Geophysical Research Letters, 42, 10,885-10,893. https://doi.org/10.1002/2015GL066764

Jones, C., Bretherton, C., \& Leon, D. (2011). Coupled vs. decoupled boundary layers in VOCALS-REx. Atmospheric Chemistry and Physics, 11(14), 7143-7153. 
Kuo, H. C., \& Schubert, W. H. (1988). Stability of cloud-topped boundary-layers. Quarterly Journal of the Royal Meteorological Society, 114(482), 887-916. https://doi.org/10.1002/qj.49711448204

Lac, C., Chaboureau, P., Masson, V., Pinty, P., Tulet, P., Escobar, J., et al. (2018). Overview of the Meso-NH model version 5.4 and its applications. Geoscientific Model Development, 11, 1929-1969.

Lilly, D. K. (1968). Models of cloud-topped mixed layers under a strong inversion. Quarterly Journal of the Royal Meteorological Society, 94(401), 292-309.

Lock, A., Brown, A., Bush, M., Martin, G., \& Smith, R. (2000). A new boundary layer mixing scheme. Part I: Scheme description and single-column model tests. Monthly Weather Review, 128(9), 3187-3199.

Mechoso, C., Wood, R., Weller, R., Bretherton, C. S., Clarke, A., Coe, H., et al. (2014). Ocean-cloud-atmosphere-land interactions in the southeastern Pacific: The VOCALS program. Bulletin of the American Meteorological Society, 95(3), 357-375.

Mellado, J. P. (2017). Cloud-top entrainment in stratocumulus clouds. Annual Review of Fluid Mechanics, 49, 145-169.

Nam, C., Bony, S., Dufresne, J. L., \& Chepfer, H. (2012). The 'too few, too bright' tropical low-cloud problem in CMIP5 models. Geophysical Research Letters, 39, L21801. https://doi.org/10.1029/2012GL053421

Neggers, R. A. J., Köhler, M., \& Beljaars, A. C. M. (2009). A dual mass flux framework for boundary layer convection. Part I: Transport. Journal of the Atmospheric Sciences, 66(6), 1465-1487.

Nicholls, S. (1984). The dynamics of stratocumulus: Aircraft observations and comparisons with a mixed layer model. Quarterly Journal of the Royal Meteorological Society, 110(466), 783-820. https://doi.org/10.1002/qj.49711046603

Nicholls, S. (1989). The structure of radiatively driven convection in stratocumulus. Quarterly Journal of the Royal Meteorological Society, 115(487), 487-511.

Park, S.-B., Gentine, P., Schneider, K., \& Farge, M. (2016). Coherent structures in the boundary and cloud layers: Role of updrafts, subsiding shells, and environmental subsidence. Journal of the Atmospheric Sciences, 73(4), 1789-1814.

Pergaud, J., Masson, V., Malardel, S., \& Couvreux, F. (2009). A parameterization of dry thermals and shallow cumuli for mesoscale numerical weather prediction. Boundary-Layer Meteorology, 132(1), 83-106.

Raupach, M. (1981). Conditional statistics of Reynolds stress in rough-wall and smooth-wall turbulent boundary layers. Journal of Fluid Mechanics, 108, 363-382.

Rio, C., \& Hourdin, F. (2008). A thermal plume model for the convective boundary layer: Representation of cumulus clouds. Journal of the Atmospheric Sciences, 65(2), 407-425.

Schumann, U., \& Moeng, C.-H. (1991). Plume fluxes in clear and cloudy convective boundary layers. Journal of the Atmospheric Sciences, 48(15), 1746-1757.

Siebesma, A.-P., Bretherton, C. S., Brown, A., Chlond, A., Cuxart, J., Duynkerke, P. G., et al. (2003). A large eddy simulation intercomparison study of shallow cumulus convection. Journal of the Atmospheric Sciences, 60(10), 1201-1219.

Siebesma, A., \& Cuijpers, J. (1995). Evaluation of parametric assumptions for shallow cumulus convection. Journal of the Atmospheric Sciences, 52(6), 650-666.

Siebesma, A. P., Soares, P. M., \& Teixeira, J. (2007). A combined eddy-diffusivity mass-flux approach for the convective boundary layer Journal of the Atmospheric Sciences, 64(4), 1230-1248.

Sušelj, K., Teixeira, J., \& Chung, D. (2013). A unified model for moist convective boundary layers based on a stochastic eddy-diffusivity/mass-flux parameterization. Journal of the Atmospheric Sciences, 70(7), 1929-1953.

Tan, Z., Kaul, C. M., Pressel, K. G., Cohen, Y., Schneider, T., \& Teixeira, J. (2018). An extended eddy-diffusivity mass-flux scheme for unified representation of subgrid-scale turbulence and convection. Journal of Advances in Modeling Earth Systems, 10, 770-800. https://doi.org/ $10.1002 / 2017$ MS001162

Wang, S., \& Stevens, B. (2000). Top-hat representation of turbulence statistics in cloud-topped boundary layers: A large eddy simulation study. Journal of the Atmospheric Sciences, 57(3), 423-441.

Williams, A., \& Hacker, J. (1992). The composite shape and structure of coherent eddies in the convective boundary layer. Boundary-Layer Meteorology, 61(3), 213-245.

Wood, R. (2012). Stratocumulus clouds. Monthly Weather Review, 140(8), 2373-2423.

Wood, R., \& Hartmann, D. L. (2006). Spatial variability of liquid water path in marine low cloud: The importance of mesoscale cellular convection. Journal of Climate, 19(9), 1748-1764.

Yamaguchi, T., \& Randall, D. A. (2012). Cooling of entrained parcels in a large-eddy simulation. Journal of the Atmospheric Sciences, 69(3), $1118-1136$. 